\title{
Duração e porcentagem de molhamento foliar determinados pelo espaçamento entrelinhas, e influência sobre a ferrugem asiática da soja
}

\author{
Wagner Teigi Igarashi ${ }^{1}$, Marcelo Augusto de Aguiar e Silva², Seiji Igarashi², Otávio Jorge Grigoli Abi Saab ${ }^{2}$, José \\ Alexandre de França ${ }^{3}$
}

\begin{abstract}
${ }^{1}$ Universidade Estadual de Londrina, Doutorando em Agronomia. Londrina, PR, Brasil; ${ }^{2}$ Universidade Estadual de Londrina, Departamento de Agronomia. Londrina, PR, Brasil. ${ }^{3}$ Universidade Estadual de Londrina, Departamento de Eng. Elétrica. Londrina, PR, Brasil.

Autor para correspondência: Wagner TeigiIgarashi (wigarashi@gmail.com)

Data de chegada: 23/01/2014. Aceito para publicação em: 10/06/2014.
\end{abstract}

$10.1590 / 0100-5405 / 1969$

\section{RESUMO}

Igarashi, W.T.; Aguiar e Silva, M.A; Igarashi, S.; Abi Saab, O.J.G.; França, J.A. Duração e porcentagem de molhamento foliar determinados pelo espaçamento entrelinhas, e influência sobre a ferrugem asiática da soja. Summa Phytopathologica, v.40, n.2, p.123-127, 2014.

A ferrugem asiática da soja causada pelo fungo Phakopsora pachyrhizi, é a doença de maior virulência e rápida disseminação da cultura no Brasil. Para que haja a infecção nas plantas são necessárias condições ambientais favoráveis, principalmente molhamento foliar quantificado pela duração do período de molhamento (DPM). Alterações no espaçamento entrelinhas de cultivo podem modificar a DPM. Este trabalho teve como objetivo verificar o efeito da utilização de dois espaçamentos entrelinhas sobre a duração e porcentagem do molhamento foliar, e a influência sobre a infecção inicial e desenvolvimento da doença. O experimento foi conduzido nas safras 2011/2012 e 2012/2013 na

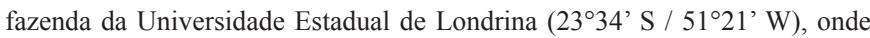
foram instalados coletores de esporo SIGA para identificar os uredósporos da P. pachyrhizi. Para quantificar a DPM e sua porcentagem foram utilizadas Árvores Eletrônicas de Molhamento, com sensores em três alturas $(0,9 \mathrm{~m} ; 0,6 \mathrm{~m}$; $0,3 \mathrm{~m}$ ), nos espaçamentos entrelinhas de $0,45 \mathrm{e} 0,8 \mathrm{~m}$. Nas safras avaliadas foram detectados uredósporos da $P$. pachyrhizi antes do aparecimento dos primeiros sintomas. Foram necessárias cerca de $6 \mathrm{~h}$ de DPM acima 50\% para que houvesse a infecção e manifestação dos sintomas de ferrugem. Foram detectadas $2 \mathrm{~h}$ a mais de DPM acima de $50 \%$ no terço médio $(0,6 \mathrm{~m})$ no espaçamento de $0,45 \mathrm{~m}$ em relação ao de $0,8 \mathrm{~m}$ em ambas as safras, no entanto não houve diferenciação na severidade entre os espaçamentos. A maior quantidade de uredósporos detectados e o volume de chuva podem explicar a maior severidade final de ferrugem na safra 2012/2013.

Palavras-chave adicionais: Phakopsora pachyrhizi, epidemiologia, coletor de esporos, sensor de molhamento foliar.

\section{ABSTRACT}

Igarashi, W.T.; Aguiar e Silva, M.A; Igarashi, S.; Abi Saab, O.J.G.; França, J.A. Leaf wetness duration and percentage based on inter-row spacing, and influence on asian soybean rust. Summa Phytopathologica, v.40, n.2, p.123-127, 2014.

The Asian soybean rust, caused by the fungus Phakopsora pachyrhizi, is the disease of greatest virulence and rapid spread affecting soybean culture in Brazil. For the infection to occur in plants, favorable environmental conditions are necessary, especially leaf wetness measured based on the leaf wetness duration (LWD). Changes in the inter-row spacing can modify the LWD. This study aimed to verify the effect of using two inter-row spacings on leaf wetness duration and percentage, as well as the influence on Asian soybean rust initial infection and development. The experiment was conducted in the crop seasons 2011/2012 and 2012/2013 at the farm of "Universidade Estadual de Londrina" ( $23^{\circ} 34$ ' $\mathrm{S} / 51^{\circ} 21^{\prime}$ W), where SIGA spore traps were installed to identify $P$. pachyrhizi urediniospores. To quantify LWD and its percentage, Electronic Trees for Wetness containing sensors at three heights $(0.9 \mathrm{~m}, 0.6 \mathrm{~m}, 0.3 \mathrm{~m})$ were used in 0.45 and 0.8 $\mathrm{m}$ inter-row spacings. During the evaluated crop seasons, P. pachyrhizi urediniospores were detected before the first symptoms. About $6 \mathrm{~h}$ of LWD over $50 \%$ were necessary for the infection to occur and for the manifestation of the first rust symptoms. Additional $2 \mathrm{~h}$ of LWD over $50 \%$ were detected in the middle third $(0.6 \mathrm{~m})$ of $0.45 \mathrm{~m}$ spacing, compared to $0.8 \mathrm{~m}$ spacing in both seasons; however, there was no difference in the disease severity between spacings. The largest number of detected urediniospores and the volume of rainfall may explain the greater final severity of soybean rust in the crop season 2012/2013.

Additional keywords: Phakopsora pachyrhizi, epidemiology, spore trap, leaf wetness sensor.

Desde a safra brasileira de 2001/2002, a ferrugem asiática da soja (FAS), causada pelo fungo Phakopsora pachyrhizi Syd. \& P. Syd., tem apresentado grande potencial destrutivo das lavouras. Em condições favoráveis a doença os danos podem ultrapassar $70 \%$ da produção, sendo necessárias aplicações de fungicidas para seu controle, aumentando o custo em áreas de cultivo de soja no Brasil (13, 21, 22).

As condições ambientais influenciam diretamente a incidência das doenças. Visando melhorar o controle da FAS, podem ser adotadas formas de manejo do microclima através de práticas culturais, como variação do espaçamento entrelinhas de cultivo da soja. O aumento do espaçamento de cultivo pode melhorar a penetração dos fungicidas, principalmente no terço médio e inferior $(3,14)$, além de favorecer um microclima de maior circulação de ar, maior temperatura, e consequentemente, menor umidade. Esta umidade relativa do ar 
favorece o molhamento foliar, termo geral utilizado para designar a presença de água na forma líquida sobre a parte aérea dos vegetais.

A duração do período de molhamento (DPM), associada a temperatura, desempenha papel fundamental em processos como a infecção e a esporulação (2). De maneira geral, temperaturas entre $18 \mathrm{e}$ $26^{\circ} \mathrm{C}$ e DPM superior a 10 horas diárias, estão associadas às condições ótimas para que se desenvolva uma epidemia severa de FAS $(2,16)$. Após a infecção, lesões e pústulas com uredósporos podem aparecer dentro de 7 ou 8 dias. Este ciclo de vida curto indica a velocidade com que ocorre a epidemia $(2,16,19)$.

O emprego de sensores eletrônicos facilita a medida da DPM. Atualmente existem vários modelos de sensores, entretanto, na sua maioria, apenas acusam a presença do molhamento, não quantificando sua porcentagem (10). Como o processo de infecção de P. pachyrhizi é dependente da área foliar molhada (1), o desenvolvimento de sensores que quantifiquem a porcentagem de molhamento foliar é importante e pode indicar com maior exatidão as condições de molhamento favoráveis ou não para o desenvolvimento epidemiológico da doença.

Apesar de todas estas informações, não se sabe ao certo o quanto a DPM é realmente modificada pelo aumento ou redução do espaçamento entrelinhas. O objetivo do trabalho foi verificar o efeito da utilização de dois espaçamentos entrelinhas sobre a duração e porcentagem de molhamento foliar, ambos em três alturas, e sua influência sobre a infecção inicial e desenvolvimento da ferrugem asiática da soja.

\section{MATERIAL E MÉTODOS}

Os experimentos foram conduzidos na área experimental da Fazenda Escola da Universidade Estadual de Londrina (UEL), no município de Londrina - PR, localizado à latitude $23^{\circ} 34^{\prime} \mathrm{S}$ e longitude $51^{\circ} 21^{\prime} \mathrm{W}$, com altitude de $560 \mathrm{~m}$, em solo classificado como Latossolo Vermelho Eutroférrico (5). De acordo com a classificação climática de Köppen, o clima da região é do tipo Cfa, com temperatura média anual de $21,1^{\circ} \mathrm{C}$ e precipitação média anual acumulada de $1600 \mathrm{~mm}$ (12).

As datas de semeadura nas duas safras foram: 1 de novembro de 2011 e 26 de outubro de 2012. A cultivar BMX Potência RR foi semeada com espaçamentos entrelinhas de 0,45 e $0,80 \mathrm{~m}$ e com 19 plantas $\mathrm{m}^{-1}$ linear. Foi feita a adubação de base com $300 \mathrm{~kg}$ por hectare de N:P:K 0:20:20. Quando necessário, foram adotados os tratos culturais e controles fitossanitários recomendados para a cultura de soja, exceto para o controle de doenças.

Cada espaçamento teve quatro repetições, totalizando oito parcelas, demarcadas com $20 \mathrm{~m}$ de largura e comprimento. No centro de cada parcela foram instalados equipamentos denominados "Árvores Eletrônicas de Molhamento" (AEM) (11), quando as plantas de soja estavam fechando as entrelinhas de cultivo, em estádio V8 da escala de Fehr \& Caviness (6) revisada por Ritchie et al. (17). Em cada uma das parcelas, foram demarcadas quatro parcelas subdivididas com $3 \mathrm{~m}$ de largura por $12 \mathrm{~m}$ de comprimento, utilizadas para a avaliação da FAS.

A partir das AEM foi possível mensurar a DPM total (horas), a DPM em porcentagem (horas), a umidade relativa do ar (\%) e a temperatura $\left({ }^{\circ} \mathrm{C}\right)$. Para a porcentagem de molhamento foliar foram utilizados valores acima de $50 \%(\mathrm{DPM}>50 \%)$ representando mais da metade da folha molhada, não sendo considerados valores abaixo deste nível. $\mathrm{O}$ molhamento foliar foi medido em três alturas $(0,90 ; 0,60$ e $0,30 \mathrm{~m})$ com quatro sensores em cada uma delas. A temperatura e umidade relativa do ar foram coletadas no abrigo meteorológico do mesmo equipamento, a 1,7 $\mathrm{m}$ de altura. A precipitação pluvial foi registrada durante a safra pela estação meteorológica da Fazenda Escola. Os dados das AEM's foram registrados automaticamente com intervalos de cinco minutos, enviados e armazenados diariamente em um servidor da UEL, desde o estádio fenológico V8 até R7.

Quando a cultura estava no estádio V4 foram instalados quatro "Coletores de esporo SIGA" (11) distribuídos nas extremidades do experimento, para determinar o momento da deposição dos primeiros uredósporos da FAS antes da manifestação dos sintomas iniciais. Lâminas de microscopia com fita adesiva de face dupla foram instaladas no tubo coletor e analisadas duas vezes por semana em microscópio óptico comum, para a identificação e quantificação dos uredósporos. A partir da detecção dos uredósporos pelo coletor de esporos SIGA, dados médios das condições meteorológicas dos sete dias posteriores foram utilizados, objetivando-se a representatividade do ambiente a que o patógeno foi submetido até a manifestação dos primeiros sintomas.

Após a aparição dos primeiros sintomas, foram feitas avaliações semanais da severidade da FAS, em quatro pontos aleatórios, estabelecidos nas parcelas subdivididas, utilizando-se escala diagramática (9). Em cada ponto foram selecionados aleatoriamente quatro folíolos no terço médio da planta. As análises dos dados foram realizadas pela estatística descritiva, realizando-se a média, desvio padrão e coeficiente de variação.

\section{RESULTADOS E DISCUSSÃO}

Na safra 2011/2012 os primeiros uredósporos da P. pachyrhizi foram detectados no momento em que a soja estava em estádio vegetativo V8, em 22 de dezembro de 2011, sete dias antes do início do florescimento. Apesar disso, não foram observados sintomas da FAS nas plantas em ambos os espaçamentos entrelinhas. Uredósporos foram detectados novamente no dia 9 de janeiro de 2012, com a soja em R2 para R3, sendo constatados sintomas iniciais da doença nos dois espaçamentos entrelinhas após uma semana.

Analisando-se os dados de sete dias posteriores à primeira detecção dos uredósporos (22/12), as condições meteorológicas médias foram de $64 \%$ de umidade relativa e $25,5^{\circ} \mathrm{C}$ de temperatura. Para os espaçamentos de 0,45 e $0,8 \mathrm{~m}$ a DPM total foi de 10,2 e $11,0 \mathrm{~h}$, e a $\mathrm{DPM}>50 \%$ foi de 3,5 e 3,2 h, respectivamente. Segundo Melching et al. (16), o mínimo de 6 horas contínuas de molhamento é requerido para que a FAS se desenvolva. Furtado et al. (8) relatam que se após 4 horas de molhamento houver uma interrupção, os uredósporos perdem sua capacidade infectiva, indicando tempo insuficiente para a penetração das hifas e intolerância a períodos secos após o início do processo de germinação. Nas 10 h de DPM total, apenas em 3,5 h houve mais de $50 \%$ das folhas molhadas, portanto os uredósporos podem não ter obtido condições ideais para infectar as plantas.

No segundo momento em que foram detectados uredósporos $(09 / 01)$ na mesma safra, os dados médios dos sete dias seguintes à detecção apresentaram valores de $80 \%$ de umidade relativa e $23^{\circ} \mathrm{C}$ de temperatura, cerca de 15,0 h de DPM total para os dois espaçamentos, e DPM $>50 \%$ de 7,3 e 5,3 h para os espaçamentos de 0,45 e $0,8 \mathrm{~m}$, respectivamente. Este molhamento foliar próximo a $6 \mathrm{~h}$ mantido acima de $50 \%$, aliado a uma temperatura mais amena e com a umidade relativa elevada, pode ter fornecido condições favoráveis para que ocorresse a infecção da FAS.

Na safra 2012/2013 uredósporos de $P$. pachyrhizi foram detectados pela primeira vez em 15 de janeiro de 2013, no estádio R5.3, sendo constatados sintomas da FAS no dia 21 de janeiro. A partir da detecção 
de uredósporos foram medidos e obtidos os seguintes dados dos sete dias posteriores: umidade relativa de $84,3 \% ; 22,9^{\circ} \mathrm{C}$ de temperatura; DPM total de $14,6 \mathrm{~h}(0,45 \mathrm{~m})$ e $14,2 \mathrm{~h}(0,8 \mathrm{~m})$; e DPM $>50 \%$ de 9,3 $\mathrm{h}(0,45 \mathrm{~m})$ e $6,7 \mathrm{~h}(0,8 \mathrm{~m})$. A umidade relativa elevada, temperatura amena e o molhamento foliar próximo a $6 \mathrm{~h}$ mantido acima de $50 \%$, foram propícios para o início da FAS no campo, do mesmo modo que no segundo momento em que foram detectados os uredósporos na safra 2011/2012.

Nas tabelas 1 e 2 foi calculada a média da DPM total e DPM $>50 \%$ do período em que a FAS foi avaliada nas safras. Analisando-se a safra 2011/2012, é observada similaridade na DPM total e DPM>50\% nos espaçamentos, à 0,9 e $0,3 \mathrm{~m}$ de altura. A exceção é observada no terço médio $(0,6 \mathrm{~m})$ no espaçamento de $0,45 \mathrm{~m}$, sendo medidas 2 horas a mais de DPM $>50 \%$ em relação ao espaçamento de 0,8 m (Tabela 1). Já na safra 2012/2013, os espaçamentos apresentaram valores diferentes entre si nas três alturas, com maior variação no terço médio $(0,6 \mathrm{~m})$, onde foi mensurado cerca de 2 horas a mais de DPM total e DPM $>50 \%$ no espaçamento de 0,45 em relação ao maior espaçamento (Tabela 2). $\mathrm{O}$ maior efeito observado à $0,6 \mathrm{~m}$ de altura pode ser atribuída às características de cada espaçamento, sendo que, devido à menor densidade de plantas por área no espaçamento de $0,80 \mathrm{~m}$, as folhas de soja fecham menos a entrelinha do que em 0,45 m. Com as entrelinhas menos densas, em 0,80 $\mathrm{m}$ há maior fluxo de vento e maior temperatura, e consequentemente menor DPM total e DPM em porcentagem.

Apesar do início de infecção da FAS ter ocorrido na metade de janeiro nas duas safras, e apresentarem severidade semelhante no estádio R5.4 (Figuras 1 e 2), o progresso temporal na severidade da doença foi diferente entre as safras. Na safra 2011/2012, em um período de 49 dias em que a FAS foi avaliada, a severidade máxima foi de 3,4 \% (Figura 1). Na safra seguinte, em um período de 30 dias, a severidade máxima foi de aproximadamente $32,9 \%$ (Figura 2).

Essa diferença se deve principalmente à quantidade de uredósporos inicialmente detectados e às condições ambientais após o início da FAS no campo. Na safra 2011/2012, do dia 9 ao dia 16 de janeiro de 2012 foram detectados dois uredósporos da FAS, sendo verificada severidade da doença inferior a 0,6 \% (valor mínimo da escala utilizada). Posteriormente, houve um período de estiagem de 14 dias, tempo em que a ferrugem não apresentou aumento de severidade na lavoura. Durante o desenvolvimento da FAS (49 dias), as condições ambientais medidas foram de temperatura média de $25,7^{\circ} \mathrm{C}, 75 \%$ de umidade relativa média e $207 \mathrm{~mm}$ de chuva em 17 dias. Os valores médios de DPM total foram de 13,5 h para os dois espaçamentos, e de $\mathrm{DPM}>50 \%$ foi $6,6 \mathrm{~h}$ e $5,8 \mathrm{~h}$ para os espaçamentos de $0,45 \mathrm{~m}$ e $0,8 \mathrm{~m}$, respectivamente (Tabela 1 ).

Na safra 2012/2013, do dia 15 à 21 de janeiro de 2013 foram detectados 128 uredósporos, com a severidade da FAS abaixo de $0,6 \%$. Durante o período de desenvolvimento da FAS (30 dias), a temperatura média foi de $22,9^{\circ} \mathrm{C}$, umidade relativa média de $85,6 \%$, com precipitação acumulada de 321,5 mm em 17 dias. Diferentemente do ocorrido na safra anterior, o período subsequente à detecção dos esporos apresentou maior volume de chuvas, conforme citado acima. Para os espaçamentos de $0,45 \mathrm{~m}$ e $0,8 \mathrm{~m}$, os valores médios de DPM foram de $15,1 \mathrm{~h}$ e $13,6 \mathrm{~h}$ e de DPM $>50 \%$ de $8,5 \mathrm{~h}$ e $7,6 \mathrm{~h}$, respectivamente (Tabela 2 ).

Tabela 1. DPM total* e DPM $>50 \% * *$ em três alturas do dossel da soja, nos espaçamento entrelinha de $0,45 \mathrm{~m}$ e $0,80 \mathrm{~m}$, do dia 9 de janeiro de 2012 ao dia 27 de fevereiro de 2012.

\begin{tabular}{|c|c|c|c|c|c|}
\hline \multirow{3}{*}{ Data } & \multirow{3}{*}{ Alt. } & \multicolumn{4}{|c|}{ Duração do Período de Molhamento (horas) } \\
\hline & & \multicolumn{2}{|c|}{$0,45 \mathrm{~m}$} & \multicolumn{2}{|c|}{$\mathbf{0 , 8 0} \mathrm{m}$} \\
\hline & & DPM total & DPM $>\mathbf{5 0} \%$ & DPM total & DPM $>\mathbf{5 0} \%$ \\
\hline \multirow{3}{*}{$\begin{array}{c}9 \text { jan }-27 \mathrm{fev} \\
(2012)\end{array}$} & $0,9 \mathrm{~m}$ & 12,8 & 5,8 & 13,2 & 5,3 \\
\hline & $0,6 \mathrm{~m}$ & 13,2 & 7,0 & 13,1 & 5,0 \\
\hline & $0,3 \mathrm{~m}$ & 14,4 & 7,0 & 14,2 & 7,2 \\
\hline \multicolumn{2}{|c|}{ Média } & 13,5 & 6,6 & 13,5 & 5,8 \\
\hline
\end{tabular}

*DPM total - Duração do período de molhamento total; **DPM $>50 \%$ - Porcentagem de molhamento de valores acima de $50 \%$

Tabela 2. DPM total* e DPM>50\%** em três alturas do dossel da soja, nos espaçamento entrelinha de $0,45 \mathrm{~m}$ e $0,80 \mathrm{~m}$, do dia 15 de janeiro de 2013 ao dia 14 de fevereiro de 2013.

\begin{tabular}{|c|c|c|c|c|c|}
\hline Data & Alt. & \multicolumn{2}{|c|}{$0,45 \mathrm{~m}$} & \multicolumn{2}{|c|}{$0,80 \mathrm{~m}$} \\
\hline \multirow{2}{*}{$\begin{array}{c}15 \text { jan }-14 \text { fe } \\
(2013)\end{array}$} & $0,9 \mathrm{~m}$ & 13,3 & 5,9 & 12,1 & 5,5 \\
\hline & $0,3 \mathrm{~m}$ & 16,2 & 9,9 & 15,0 & 9,7 \\
\hline Média & & 15,1 & 8,5 & 13,6 & 7,6 \\
\hline
\end{tabular}

*DPM total - Duração do período de molhamento total; **DPM $>50 \%$ - Porcentagem de molhamento de valores acima de $50 \%$. 


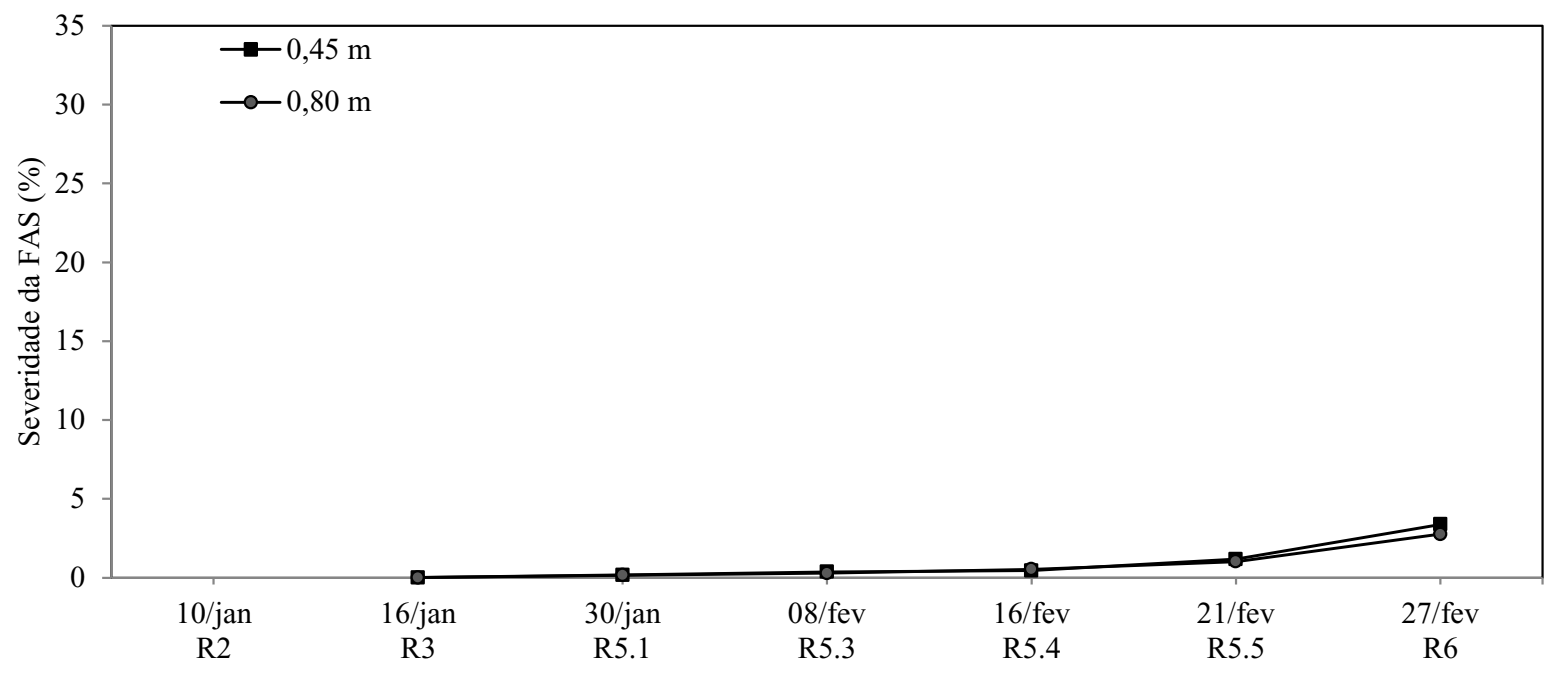

Figura 1. Avaliações de severidade da FAS nos espaçamento entrelinhas de 0,45 e 0,80 m, na safra 2011/2012 de soja.

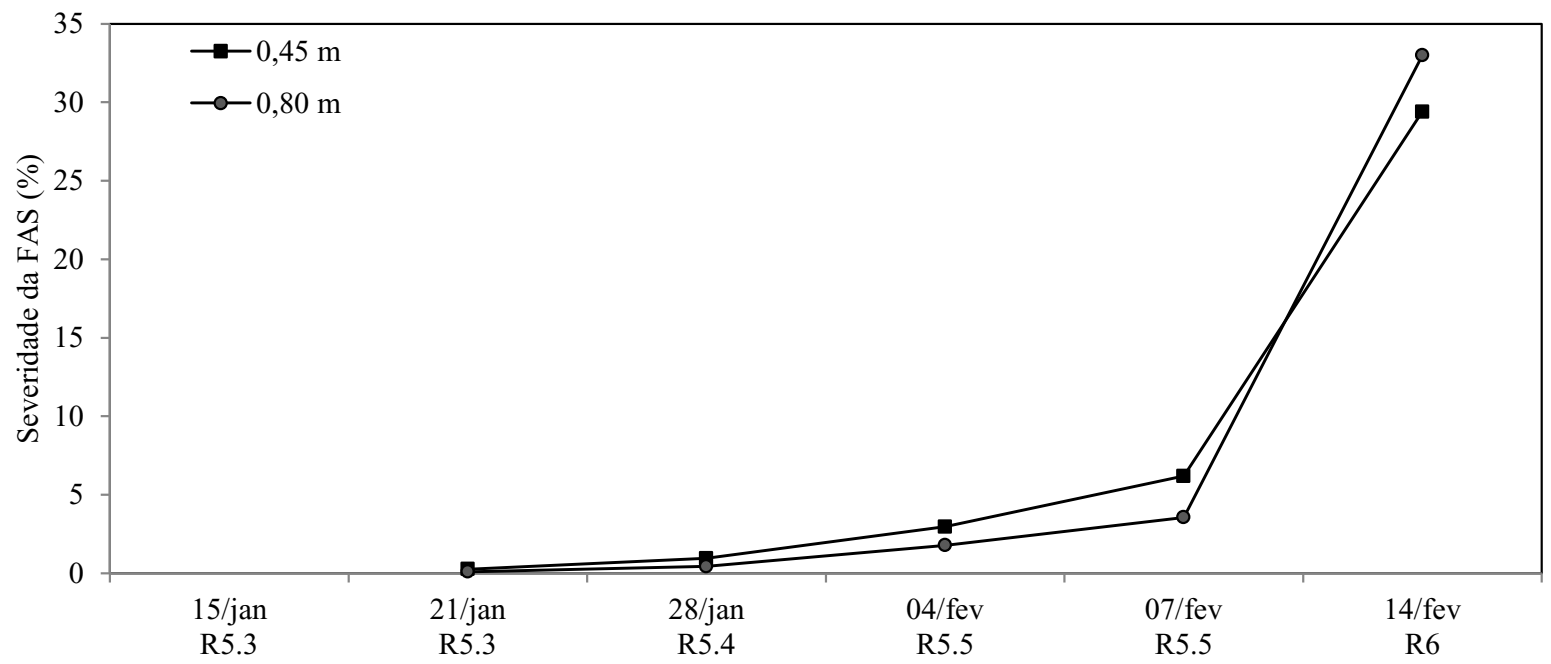

Figura 2. Avaliações de severidade da FAS nos espaçamento entrelinhas de 0,45 e 0,80 m, na safra 2012/2013 de soja.

A combinação de condições meteorológicas mais favoráveis e maior quantidade uredósporos iniciais podem explicar a diferença na severidade final da FAS nas duas safras. Dentre os fatores meteorológicos destaca-se a presença de chuva, resultando em temperaturas mais amenas e o ambiente com maior umidade relativa, aumentando a DPM e favorecendo as doenças. O maior volume de chuvas com maior regularidade na safra 2012/2013 proporcionou dias com média de $10 \%$ a mais de umidade relativa e temperatura $3{ }^{\circ} \mathrm{C}$ menores que a safra anterior, proporcionando condições mais favoráveis ao desenvolvimento da FAS. Estudos feitos em Taiwan (20) mostram que a chuva tem um efeito direto na epidemia da FAS por estar relacionada com a dispersão dentro do dossel da cultura, principalmente nos estágios iniciais da doença. Estes efeitos estão relacionados com o impacto das gotas de água que dispersam os uredósporos entre as folhas da soja $(7,15)$. O modelo de previsão da FAS desenvolvido por Del Ponte et al. (4), demonstrou que a chuva pode ser um prognosticador da severidade final da doença, explicando de 85 a $93 \%$ da variação da severidade máxima. Os dados mencionados acima e os descritos neste experimento destacam a importância do monitoramento das condições meteorológicas da lavoura após a detecção de esporos da FAS na área, quando se usa equipamentos como o coletor de esporos SIGA. Se houver a probabilidade de ocorrência da chuva, há a necessidade de iniciar medidas de prevenção da infecção pela $P$. pachyrhizi.

Ainda analisando as safras separadamente, verifica-se que a detecção dos primeiros sintomas da FAS ocorreu no mesmo momento nos dois espaçamentos, e que a severidade final foi semelhante entre os espaçamentos. Deste modo, entende-se que o aumento de espaçamento para $0,8 \mathrm{~m}$ não influenciou na infecção e no desenvolvimento da FAS (Figuras 1 e 2). Este resultado concorda parcialmente com os resultados obtidos por Roese et al. (18), os quais analisaram três safras e o espaçamento influenciou somente a severidade da terceira safra (2010/2011). Estes autores avaliaram quatro espaçamentos entrelinhas $(0,35 ; 0,45 ; 0,55$ e $0,65 \mathrm{~m})$, e em cada safra foram utilizadas diferentes cultivares em diferentes épocas de semeaduras. As cultivares semeadas nas duas primeiras safras são de ciclo médio, e na terceira safra a cultivar é de ciclo semi precoce, o que pode justificar a diferença obtida no experimento. No presente trabalho o espaçamento entrelinhas não foi um fator limitante à doença, apesar da duração e porcentagem do 
molhamento foliar apresentar variações a $0,6 \mathrm{~m}$ de altura entre os espaçamentos.

O coletor de esporos SIGA mostrou-se viável como sistema de previsão da FAS na detecção dos uredósporos no ar antes de sua infecção efetiva sobre a cultura. A mensuração da porcentagem de molhamento se mostra importante, pois sensores que detectam apenas a presença da água podem superestimar o molhamento quando este ocorre em baixas proporções, como observado na primeira detecção de uredósporos de P. pachyrhizi na safra 2011/2012.

\section{AGRADECIMENTOS}

À CAPES - Coordenação de Aperfeiçoamento de Pessoal de Nível Superior, pelo apoio financeiro.

\section{REFERÊNCIAS BIBLIOGRÁFICAS}

1. Bedendo, I.P. Ambiente e doença. In: Bergamin Filho, A.; Kimati, H.; Amorin, A. Manual de fitopatologia. 3. ed. São Paulo: Agronômica Ceres, 1995. v.1, p.331-341.

2. Bonde, M.R.; Berner, D.K.; Nester, S.E.; Frederick, R.D. Effects of temperature on urediniospore germination germ tube growth, and initiation of infection in soybean by Phakopsora isolates. Phytopathology, St. Paul, v.97, n. 8, p.997-1003, 2007.

3. Debortoli, M. P.; Balardin, R. S.; Possebon, R.; Zimmermann, A.; Cerbaro, L. Efeito do arranjo de plantas sobre o progresso de ferrugem asiática na soja. Revista da Sociedade Brasileira de Fitopatologia, Brasília, v.31, n.1, p.129, 2006.

4. Del Ponte, E.M., Godoy, C.V., Li, X., Yang, X.B. Predicting severity of Asian soybean rust with empirical rainfall models. Phytopathology. St. Paul, v.96, p.797-803. 2006.

5. Embrapa. Centro Nacional de Pesquisa de Solos (Rio de Janeiro, RJ). Sistema brasileiro de classificação de solos. Rio de Janeiro: EMBRAPA-SPI, 2009.

6. Fehr, W.R, Caviness, C.E. Stages of soybean development. Iowa State University of Science and Technology, Ames, 11p. (Special Report, 80). 1977.

7. Fitt, B.D.L.; Mccartney, H.A., Walklate, P.J. Role of rain in the dispersal of pathogen inoculum. Annual Review of Phytopathology, Palo Alto, v.27, p.241-270, 1989.

8. Furtado, G.Q.; Moraes, R.S.G.; Alves, S.A.M.; Amorin, L.; Massola Júnior, N.S. The Infection of Soybean Leaves by Phakopsora pachyrhizi during Conditions of Discontinuous Wetness. Journal of Phytopathology,
Hoboken, v.159, p.165-170. 2010.

9. Godoy, C.V.; Koga, L.J., Canteri, M.G. Diagrammatic scale for assessment of soybean rust severity. Fitopatologia Brasileira, Brasília, DF, v.31, n.1, p.63-68, jan./fev. 2006.

10. Guedes, A.L.; Moreira, M.; França, M.B. de M.; França, J.A. de; Piai, J.C.; Aguiar e Silva, M.A. de; Canteri, M.G. A distributed and wireless data acquisition system to fight against sugarcane orange rust. Controle $\mathbb{\&}$ Automação, Campinas, v.65, p. 1-13, 2013.

11. Igarashi, S.; Balan, M.G. Ferrugem na soja. Direto do Vale. Vale do Paranapanema. v.1, p.1-8, 2004.

12. Instituto Agronômico do Paraná - IAPAR. Médias Históricas. Disponível em: http://www.iapar.br/arquivos/Image/monitoramento/Medias_Historicas/Londrina.htm. Acesso em: 10/04/2013.

13. Ito, M.F.; Miranda, M.A.C.; Braga, N.R.; Miranda, F.T.S. Ocorrência de ferrugem em soja, nos compostos IAC, macho-estéreis,em Campinas-SP In: Reunião de Pesquisa de Soja da Região Central do Brasil. 24., 2002, São Pedro. Anais. Londrina: Embrapa Soja, 2002. p.246.

14. Madalosso, M.G.; Domingues, L.daS.; Debortoli, M.P.; Lenz, G.; Balardin, R.S. Cultivares, espaçamento entrelinhas e programas de aplicação de fungicidas no controle de Phakopsora pachyrhizi Sidow em soja. Ciência Rural, Santa Maria, v. 40, n.11, p.2256-2261, nov. 2010.

15. Madden, L.V. Rainfall and dispersal of fungal spores. Advances in Plant Pathology, Madison, v.8, p.39-79, 1992.

16. Melching, J.S., Dowler, W.M., Koogle, D.L. \& Royer, M.H. Effects of duration, frequency, and temperature of leaf wetness periods on soybean rust. Plant Disease, St. Paul, v.73, p.117-122, 1989.

17. Ritchie, S.W.; Hanway, J.J.; Thompson, H.E.; Benson, G.O. How a soybean plant develops. Ames, Iowa State University of Science and Technology: Cooperative Extension Service, 1994. 20p. (Special Report, 53).

18. Roese, A.D.; Melo, C.L.P.; Goulart, A.C.P. Espaçamento entre linhas e severidade da ferrugem-asiática da soja. Summa Phytopathologica, Botucatu, v.38, n.4, p.300-305, 2012.

19. Rupe, J.; Sconyers, L. Soybean rust. Ames, 2008. Disponível em: http:// www.apsnet.org/edcenter/intropp/lessons/fungi/Basidiomycetes/Pages/ SoybeanRust.aspx. Acesso em: 12/12/2013.

20. Tschanz, A.T. Soybean rust epidemiology: final report. Asian Vegetable Research and Development Center, Shanhau, Taiwan. 1982. In: Del Ponte, E.M., Godoy, C.V., Li, X., Yang, X.B. Predicting severity of Asian soybean rust with empirical rainfall models. Phytopathology, St. Paul, v.96, p.797-803. 2006.

21. Yorinori, J.T. Ferrugem da soja: panorama geral. In: VII World Soybean Research Conference, IV International Soybean Processing and Utilization Conference, III Congresso Brasileiro de Soja, 7., 2004, Foz do Iguaçú. Proceedings. Foz do Iguaçú: EMBRAPA, 2004, p.1299-1307.

22. Yorinori, J.T.; Paiva, W.M.; Frederic, R.D.; Fernandez, P.F.T. Ferrugem da soja (Phakopsora pachyrhizi) no Brasil e no Paraguai, nas safras 2000/01 e 2001/02. In: II Congresso Brasileiro de Soja, 2., 2002, Foz do Iguaçu. Anais. Londrina: EMBRAPA, 2002, p.94. 